\title{
A ficção nossa de cada dia: para uma leitura crítica da telenovela pautada por uma teoria das mediações
}

Maria Isabel Orofino*

Professora de Comunicação Social - Centro de Artes - UDESC. Doutora pela

Escola de Comunicações e Artes, Universidade de São Paulo (ECA/USP), com estágio na London School of Economics and Political Sciences/London University. Jornalista e roteirista profissional de programas educativos e culturais para televisão, vídeo e teatro.

E-mail: isabelorofino@hotmail.com

Resumo: Este artigo discute novas possibilidades de análise crítica da telenovela brasileira para além de uma leitura linear de causa e efeito, mas sim enquanto "texto em aberto", a partir do qual se torna possível compreender um amplo diálogo social em que o público, muitas vezes, é interpelado a participar da feitura da obra. Esta evidência demonstra que precisamos entender a presença da telenovela não como imposição da indústria cultural, mas como narrativa que ativa competências culturais e na qual as classes populares se reconhecem.

Palavras-chave: telenovela, mediações, diálogo social, obra em aberto.
Absract: The article presents new possibilities for a critical analysis of the brazilian telenovelas. Moving beyond a linear causeand-effect reading, the author proposes that the telenovela be understood as an open text in a wide social dialogue in which, frequently, the public is interpellated to participate. This evidence shows that it is necessary to understand the presence of the telenovela not as an imposition of the culture industry but also as a narrative which activates cultural competences and promotes the recognition of the popular classes.

Keywords: telenovela, mediations, social dialogue and open text.

Será importante tratar de televisão em tempos de internet? Temos assistido ao crescimento exponencial dos usos e consumo do computador, em especial da internet, na vida cotidiana dos brasileiros. Não há dúvidas de que o que comumente se chama de multimídia coloca em pauta a questão da convergência tecnológica e deflagra a construção de um novo cenário cultural,

Recebido: 11/02/2008

Aprovado: 03/03/2008

* Participou da pesquisa Vivendo com a telenovela: mediações, recepção e teleficcionalidade (Lopes, Borelli e Resende, 2002). Traduziu Multiculturalismo Crítico (de Peter McLaren, São Paulo, Cortez, 1997) e Crescer na era das mídias (de David Buckingham, São Paulo, Loyola, 2007). Publicou recentemente Mídias e mediação escolar (São Paulo, Cortez, 2005) e Mediações na produção de televisão (EdiPUCRS, 2006). 
1. Mapa da Exclusão Digital. Fundação Getúlio Vargas. Disponível em: $<$ http://www2.fgv.br/ ibre/cps/mapa_exclusao/ SUMARIO/sumario\%20 interativo.htm>.

2. WILLIAMS, Raymond. The Long Revolution (A longa revolução). London: Penguin Books, 1965

3. You Tube: site na rede mundial de computadores (world wide web), no qual qualquer pessoa pode hospedar os seus vídeos. Nos últimos anos este espaço se tornou muito popular entre os usuários da web. que precisa ser levado em conta quando o problema em foco é a presença das mídias na vida social. O computador torna-se local tanto de integração quando de exclusão. Por um lado ele possibilita a comunicação, a produção criativa de novas formas culturais e a democratização do debate público ao viabilizar a ampliação e amplificação de novas narrativas que surgem como respostas vindas de variados públicos. Por outro lado, estes novos meios, na medida em que promovem integração ainda são inacessíveis a grandes parcelas da população mundial. Dados estatísticos levantados pela Fundação Getúlio Vargas revelam que no Brasil, no ano de 2001, apenas 8,31\% da população tinha acesso à internet ${ }^{1}$.

Mesmo diante da emergência deste novo cenário midiático, ainda continua importante a reflexão sobre formas culturais que tiveram o seu momento áureo em décadas passadas, como o livro, o jornal impresso, o rádio, o filme, os quadrinhos, a pintura, a fotografia, entre outros. Para uma pedagogia crítica da mídia na escola é preciso considerar o conjunto dos meios de comunicação na construção de representações sociais a partir das quais compartilhamos um imaginário social. Afinal, uma das maiores riquezas que a multimídia nos apresenta é justamente a possibilidade de criarmos e produzirmos textualidades com os recursos da convergência tecnológica e, assim, nos lançarmos na aventura da criação de novas formas culturais.

Neste contexto, convém lembrar a proposta metodológica de Raymond Williams ${ }^{2}$, ao enfatizar que em nossos estudos particulares, ou seja, nossa prática de produção e reflexão sobre a mídia, seja ela na escola, seja fora dela, é preciso levar em consideração o conjunto total de uma dada formação, a sua organização geral, e relacionar os seus elementos no que concerne: às condições materiais, às determinações econômicas, às formas culturais, a seus autores, bem como às comunidades de receptores.

Com esta introdução, faz-se uma justificativa da contínua importância do papel que a velha TV desempenha quando estamos tratando de produção e consumo cultural nas sociedades periféricas contemporâneas. No Brasil e na vasta maioria dos países latino-americanos, a televisão continua sendo o meio de comunicação que alcança a maior parcela da população. Ela cobre 99,8\% do território e, em especial, a Rede Globo de televisão é aquela que ainda detém a hegemonia tecnológica nos sistemas de difusão, o que faz com que ainda o seu sinal tenha melhor qualidade de recepção nos aparelhos dos lares brasileiros.

A proposta desta crítica será debater algumas evidências empíricas que revelam existir uma nova teoria sobre a telenovela, que a problematiza enquanto espaço de diálogo social e que a compreende como um dos programas de TV mais populares do Brasil. O que reafirma a sua importância. Afinal, mesmo em tempos de YouTube ${ }^{3}$, a telenovela continua a mobilizar grandes audiências e se consolida como um canal de reconhecimento, criatividade, articulação, debate e diálogo social. Para realizar esta discussão, será tomado como referência um conjunto teórico particular desenvolvido 
na América Latina chamado teorias das mediações. Em segundo lugar será sugerida uma reflexão sobre a telenovela enquanto texto em aberto, o que nos possibilita uma leitura menos maniqueísta, tanto da mídia em geral quanto de seus produtos em particular.

\section{TELEVISÃO E TEORIAS DAS MEDIAÇÕES}

No ano 2000 foi possível acompanhar um amplo debate sobre a presença e importância da TV em nosso país. Ali, completavam-se 50 anos de história da TV brasileira a partir da data de implantação da TV Tupi Difusora, cujo proprietário foi Assis Chateubriand. Qualquer pretensão de análise crítica sobre este meio de comunicação precisa levar em conta que a TV já faz parte de nossa realidade sociohistórica há mais de 50 anos e que, portanto, é com ela que construímos boa parte de nossa memória social recente, seja a partir dos relatos do telejornalismo, seja pela fruição das obras de ficção, da publicidade ou mesmo com as glórias e derrotas do nosso esporte.

Ao longo deste período a televisão brasileira construiu um repertório que, na maioria das vezes, é duramente criticado como baixa cultura. Aliás, é o que também acontece com relação aos demais produtos da chamada cultura de massas ${ }^{4}$. Isto é, a crítica especializada toma a TV como alvo de denúncias e acusações por diferentes atores sociais: por um lado, os mais conservadores, inclusive religiosos, atacaram a TV como sendo espaço de excessiva abertura e exposição sexual diante das novas gerações e do incentivo à ruptura com valores familiares. Por outro, uma crítica de esquerda (Economia Política e Indústria Cultural) condena os vínculos da TV aos interesses perversos da sociedade de mercado e a conseqüente padronização e empobrecimento estético do que ela oferece.

Hoje, é possível mapear novos olhares, tanto sobre a cultura de massas em geral (se é que se pode ainda usar este conceito após o advento dos estudos de recepção) quanto com relação à produção de TV.

Arlindo Machado, por exemplo, em seu A TV levada a sério ${ }^{5}$, propõe uma reflexão sobre o amplo acervo de produtos que se tornam particulares na história da cultura brasileira e que têm sua origem na TV. Cito aqui, como exemplos, concordando com a sua hipótese, em especial o requinte de produção das minisséries brasileiras, a singularidade autoral de determinados escritores de telenovela como Dias Gomes, Janete Clair e Gilberto Braga e a inovação de alguns programas infantis, como $O$ castelo Rá-tim-bum (TV Cultura - SP).

Antes mesmo de Machado propor este olhar diferenciado com relação às textualidades da TV, um marco teórico fundamental na América Latina se dá com o desenvolvimento do trabalho de Jesús Martín-Barbero e a chamada teoria das mediações, cujo debate internacional ocorre de modo irreversível a partir dos anos 1980.
4. BUCKINGHAM, David. Crescer na era das mídias. São Paulo: Loyola, 2007.

5. MACHADO, Arlindo. A TV levada a sério. São Paulo: SENAC, 2001. 
6. OROFINO, Maria Isabel. Mídias e mediação escolar: pedagogia dos meios, participação e visibilidade. São Paulo: Cortez. 2005

7. WOLF, Mauro. Teorias da Comunicação. Lisboa: Presença, 1987.

8. OROFINO, Maria Isabel. Mediações na produção de teleficção: um estudo sobre o Auto da Compadecida. Porto Alegre: EdiPUC, 2006

9. BUCKINGHAM, David. Crescer na era das mídias. São Paulo: Loyola, 2007. p. 153 comunicação \& educação • Ano XIII • Número 2 • maio/ago 2008

As teorias das mediações na América Latina marcam um elo, uma conexão com um debate internacional mais amplo que fora lançado pelos autores dos Estudos Culturais de Birgmingham. No entanto, e até onde se pode compro$\operatorname{var}^{6}$, as teorias latino-americanas propõem um modelo ainda mais integrador, convergente e de complexidade.

Em síntese, os autores vinculados aos Estudos Culturais britânicos, desconfiados de uma crítica puramente maniqueísta com relação à mídia, se debruçaram sobre o pólo da recepção a partir de uma teoria crítica. As audiências já haviam sido problematizadas por estudos funcionalistas, como a pesquisa dos efeitos e usos e gratificações ${ }^{7}$ (isto é: o consumo cultural, os modos como as pessoas em seu cotidiano aceitam, ignoram, recusam ou criticam os conteúdos veiculados pela mídia, e a TV em particular). Ao indagar sobre como as pessoas usam, recusam ou recriam os conteúdos da mídia, foi possível desafiar as visões dominantes sobre os seus vínculos e articulações com a ideologia dominante e suas formas de poder. Portanto, a grande contribuição dos Estudos Culturais britânicos é justamente a produção de um amplo referencial, fortemente ancorado em pesquisas empíricas com muitos estudos de recepção que comprovam a hipótese de que os receptores não são necessariamente sujeitos passivos diante dos apelos sedutores da mídia. Os sujeitos sociais produzem leituras diferenciadas dos conteúdos veiculados a partir de seus repertórios e contextos culturais particulares ${ }^{8}$.

A tese do receptor ativo tornou-se quase uma obsessão em todo o mundo e os Estudos Culturais se multiplicaram como uma nova disciplina, com especificidades em diferentes continentes. Em meados dos anos 1990, a ampla repercussão desta hipótese levou a teoria da comunicação ao risco do que se chamou de populismo cultural, que liberou a mídia de uma crítica mais substantiva, uma vez que já não havia mais problemas de manipulação e/ou alienação. A velha tese frankfurtiana da Indústria Cultural podia agora ser colocada de lado, pois, afinal de contas, os consumidores são ativos e críticos. Para nós, ainda jovens estudiosos no campo, aquele momento foi quase como um convite a pendurar as chuteiras, tal como: ótimo, não precisamos fazer mais nada!

Outra questão problemática: mesmo que os receptores sejam ativos, o pólo da produção continuava a ser compreendido como o lado ruim, o vilão da história, de onde provêm discursos sempre comprometidos com a ideologia dominante, nunca havendo uma brecha ou contradição.

Sabemos que não é assim: a própria telenovela, por exemplo, coloca em pauta uma série de questões políticas como exclusão social, discriminação racial, emancipação com relação a conflitos de classe, de gênero e orientação sexual. O importante é realizarmos uma crítica que consiga distinguir entre as estratégias da ideologia dominante e os modos como autores criativos driblam essas imposições e constroem novas possibilidades narrativas.

Sob o ponto de vista de uma teoria crítica da comunicação, corremos o risco também de incorrer em um movimento pendular ${ }^{9}$. Segundo David Buckingham: 
É possível ver a história da pesquisa acadêmica sobre a audiência como um contínuo processo de reação, como um pêndulo que balança constantemente entre mídia poderosa e público poderoso [...]. O público - afirma-se repetidamente - não se compõe de bobalhões dopados pela influência da mídia. Ao contrário, ele faz julgamentos complexos e diferenciados a respeito do que lê e assiste. É ativo e não passivo; criterioso e não inconsciente; diversificado e não homogêneo. Como fica implícito, é freqüente nestes debates uma lógica dual implacável: ou é uma coisa ou é outra; isto é o que, a meu ver, precisa urgentemente ser questionado.

De análises ancoradas em uma economia política da produção, passamos para as análises de discurso e conteúdo das mensagens e caímos no pólo da recepção sem conseguir estabelecer os nexos entre estes três diferentes momentos do processo de comunicação (produção - mensagem - recepção).

Mesmo que autores seminais e importantíssimos como Raymond Williams e Stuart Hall tivessem proposto a articulação entre os diferentes momentos do processo de comunicação, foi possível verificar, em uma análise detalhada ${ }^{10}$, que Jesús Martín-Barbero e Guillermo Orozco foram os autores que conseguiram traduzir metodologicamente uma proposta convergente e integradora para se pensar as mediações nos diferentes processos da comunicação social nas sociedades contemporâneas.

Portanto, as teorias das mediações são aquele conjunto que se origina no campo da comunicação social na América Latina. É preciso destacar que o debate em torno do conceito de mediação possui uma ampla trajetória, que vem desde a filosofia hegeliana e se estende por diferentes enfoques na teoria marxista da arte (Bloch, Lukács, Adorno, Benjamin, entre outros). E também em uma teoria política, como a de Gramsci, que problematiza a reflexividade e a capacidade transformadora dos educadores e intelectuais, por exemplo.

Neste sentido, pensar as mediações a partir da TV significa, antes de tudo, compreendê-la como um local de contradições e ambigüidades, seja: (a) a partir das análises das diferentes leituras que ocorrem na recepção; (b) na análise crítica dos seus produtos e textualidades, ou (c) na inserção criativa e transformadora de determinados profissionais que atuam por dentro das estruturas de produção e formulam propostas de ruptura e inovação formal por dentro mesmo dos interesses perversos do mercado e driblam as estratégias do poder estabelecido.

O principal avanço, considero, ocorre a partir das teorias latino-americanas das mediações, e, ainda, pensar que o que se produz na TV e em outras mídias pode ser resultado também da reflexividade de autores criativos que buscam a participação de seus públicos em particular, os quais produzem mecanismos de respostas que são mediadas em um amplo debate social.

Para encerrar esta parte: se por um lado os Estudos Culturais contribuíram com a construção de evidências empíricas sobre as atividades dos receptores, as teorias das mediações, ao incorporar esta visão, não excluem as demais dimensões do processo e buscam indagar sobre os modos de endereçamento e resposta, situando a comunicação como processo cultural e sociohistórico.

10. OROFINO, Mídias e mediação escolar, op. cit. 
Busca-se, portanto, integrar as diferentes partes de um conjunto total de uma dada formação, a sua organização geral e relacionar os seus elementos em relação, como destacamos no início deste texto.

\section{A TELENOVELA NOSSA DE CADA DIA}

Colocada sobre um muro, ou mesmo no centro de uma pequena praça ou dentro de casa, geralmente na sala de jantar, nas moradias mais variadas em todo o país, pessoas diferentes sintonizam a antena para poder acompanhar a programação da TV, que segundo os estudos de recepção é muito mais do que meio de comunicação. Ela é também uma companheira para a solidão, um eletrodoméstico que fala, faz rir e chorar as mais diferentes pessoas, das mais variadas classes sociais, etnias, orientações sexuais e religiões. Somente a Rede Globo mantém, há mais de trinta anos, uma média de quatro telenovelas com exibições diárias, e outros programas de ficção como minisséries, casos especiais e comédias seriadas.

É certo que em anos recentes temos visto a retomada, por parte de outras emissoras nacionais, da produção de novos programas de ficção televisiva seriada, como é o caso da Rede Record e do SBT, que passam a competir com a hegemonia da Rede Globo na disputa pela audiência quase cativa do público brasileiro com a sua preferência pelo produto telenovela ${ }^{11}$. Afinal, ao mobilizar tamanha atenção do público em todo o país, ela alcança índices de audiência que motivam investidores e anunciantes, o que faz com que seja um dos produtos televisivos mais rentáveis da produção nacional. O público gosta e a indústria cultural investe e precisa dela.

A questão aqui é problematizar justamente o porquê de o público gostar tanto de telenovela. A teoria crítica da Indústria Cultural poderia inferir que a telenovela é meramente um produto que glamouriza a pobreza, valoriza os ideais das classes dominantes e perpetua as relações assimétricas de poder propagando, portanto, a alienação de seu público. Os Estudos Culturais poderiam destacar que nem tanto importa os valores dominantes implícitos no texto; a questão é que os receptores têm competências para usar e recusar aquilo que vem da indústria. Já uma teoria crítica das mediações levaria em consideração as hipóteses anteriores e, sem desconsiderá-las, agregaria novos elementos de complexidade, buscando indagar, por exemplo, sobre que fatores levam a telenovela a ser tão amplamente consumida por um público culturalmente competente. Segundo Jesús MartínBarbero $^{12}$, a telenovela recupera um sentido de pertença a uma dada realidade cultural, promove modos de reconhecimento do público na obra e resgata competências culturais que são históricas e que vêm de outras experiências, como a fruição do romance de folhetim, do circo e da radionovela, por exemplo, na medida mesmo em que tematiza a contemporaneidade da vida social de um país. Para Martín-Barbero, a forte presença da telenovela na cultura latino-americana pode ser compreendida a partir de três dimensões: a cotidianidade familiar, a 
competência cultural e a temporalidade social. Na seqüência, uma breve explicação sobre o que ele propõe com esta estruturação:

a) A telenovela atua como uma extensão da vida familiar: conflitos vividos no espaço doméstico da família são tematizados todos os dias nos muitos capítulos da ficção seriada, de modo que ela promove um prolongamento do que vivemos em família, nossos dramas, nossas perdas e alegrias. Segundo Roger Silverstone, a teleficção seriada "atua como um coro grego para o drama da vida social" ${ }^{\prime \prime}$.

b) A telenovela ativa competências culturais que vêm de formas culturais anteriores, seja o circo, as comédias, os dramas do rádio ou o sucesso de determinados temas musicais.

c) A telenovela dialoga com tempo vivido na sociedade, o que o autor chama de temporalidade social. Se estamos vivendo o Natal, as ceias também ocorrem na telenovela; no Ano-Novo, há fogos de artifício; se é hora de voltar às aulas, se há eleições no país, tudo é retratado; e se é carnaval, os ensaios no barracão acontecem no meu bairro e também no texto da telenovela; e a peruca de determinada personagem invade as bancas dos camelôs para ser usada pelos blocos de sujo em várias regiões do país, como foi o caso da peruca da personagem Branca, de Duas Caras $^{14}$, no Carnaval de 2008.

Mais do que dominação, a telenovela promove diálogo social e, em certa medida, apresenta uma resposta do terceiro mundo às imposições vindas do Norte para nos tornarmos fiéis consumidores dos programas enlatados de outras terras. Afinal, apesar das mudanças recentes com a retomada das séries estadunidenses como Lost, por exemplo, a telenovela brasileira havia alcançado ampla aceitação no mercado internacional, tornando-se o produto cultural mais exportado fora do Brasil, sendo que mais de cem países compram nossa produção televisiva ${ }^{15}$.

\section{CARACTERÍSTICAS FORMAIS: POR UMA DIALÉTICA DO "TEXTO EM ABERTO"}

À guisa de exemplo, destaca-se como a telenovela Duas Caras nos oferece ótimas evidências de como operam alguns mecanismos de ativação das audiências. Uma característica formal que é única da telenovela brasileira: o texto em aberto.

Quero me referir aqui às estratégias que vêm da produção e se efetivam em modos de endereçamento e que, no caso da telenovela, buscam respostas rápidas, vindas do público. São mecanismos narrativos que consagram o gênero enquanto forma cultural do texto em aberto ${ }^{16}$, uma característica muito própria da telenovela brasileira: comunicação com endereço e resposta. É a telenovela mostrando evidências de participação e diálogo social.
13. SILVERSTONE, Roger. Television and everyday life (Televisão e vida cotidiana). London: Routledge, 1994.

14. De Aginaldo Silva e Direção de Wolf Maia. Rede Globo de Televisão, out. 2007.

15. MELO, José Marques de. As telenovelas da Globo: produção e exportação. São Paulo: Summus, 1988.

16. Ver: PALLOTTINI, Renata. Dramaturgia de televisão. São Paulo: Moderna, 1998. 
17. De Gilberto Braga e Ricardo Linhares. Direção de Denis Carvalho e José Luiz Villamarim. Rede Globo de Televisão, mar./ set. 2007

18. De Gilberto Braga. Direção de Denis Carvalho e Ricardo Waddington. Rede Globo de Televisão maio 1988/jan. 1989.

19. De Daniel Filho e Gonzaga Blota. Direção de Daniel Filho. Rede Globo de Televisão, dez. 1977/jul. 1978.

20. ECO, Umberto. Obra aberta. 9. reimpr. São Paulo: Perspectiva, 2007.

21. MARTÍN-BARBERO, Dos meios às mediações, op. cit.

* Ver: PAULA, Luiz Antonio de. A desconstrução do suspense na telenovela pela valorização do saber antes. Comunicação \& Educação. São Paulo: CCA-ECA-USP/ Paulinas, n. 1, jan./abr. 2008. (N.E.) comunicação \& educação • Ano XIII • Número 2 ・ maio/ago 2008

$\mathrm{Na}$ trama, com a invasão da favela da Portelinha e o suspense em torno da morte do personagem de Juvenal Antena, o autor Aguinaldo Silva inverteu o jogo: saiu do terreno sombrio marcado por baixos índices de audiência e alcançou ampla mobilização do seu público, além de elevar Juvenal Antena à galeria dos personagens inesquecíveis. $\mathrm{O}$ fato nos mostra também uma marca de autor. Diferentemente da estratégia de Gilberto Braga com a personagem Thaís, em Paraíso Tropical ${ }^{17}$ (Rede Globo, 2007), Silva repetiu a fórmula usada por ele próprio em outra novela, Vale $T u d o^{18}$, com a personagem de Odete Roitman (mas, de fato, a primeira a utilizar essa marca foi Janete Clair em O Astro ${ }^{19}$, com o suspense sobre quem matou Salomão Hayala?). Em Duas Caras, o que temos é: o Juvenal vai morrer? Trata-se do recurso da clássica trajetória do herói: o semideus que precisa morrer por alguns minutos ou horas para construir a catarse com a sua ressurreição.

O que se deseja destacar aqui é a relação entre produção e audiência. Ao contrário do conceito de obra aberta, como proposto por Umberto $\mathrm{Eco}^{20}$, em que a produção de sentido se completa na leitura do receptor, a obra $\mathrm{em}$ aberto se constrói no diálogo que se tece na relação com a audiência durante a sua feitura, bem como por meio da incorporação de demandas que vêm do público nesta obra. E esta é, como bem sabemos, uma das convenções formais mais evidentes da telenovela brasileira.

Se analisados sob o prisma de uma teoria das mediações, os episódios marcantes de Duas Caras, exibidos na primeira semana de janeiro de 2008, nos permitem compreender como a estratégia do autor em divulgar e realizar uma falsa morte do herói evidencia uma operação de sentido (como destacada por MartínBarbero $^{21}$ ) e que conecta os diferentes momentos do processo de comunicação: do sistema de difusão, à produção, realização do texto, processos de recepção e principalmente de respostas do público à produção e da produção ao texto, e por aí adiante. Uma síntese de um amplo diálogo social que contradiz grande parte das teorias dominantes sobre a presença das TVs abertas nas sociedades contemporâneas e que faz da telenovela brasileira um locus privilegiado para a sua observação.

Por exemplo, duas semanas antes de os capítulos irem ao ar, a imprensa publicou declarações do autor Aguinaldo Silva afirmando que ele mataria o personagem. A notícia se espalhou, tanto por meio dos semanários quanto por revistas de divulgação da telenovela (Minha Novela; Ti-ti-ti; TV + Novelas; Guia $d a T V$ ), e foram coadjuvantes na difusão da informação sobre a ousadia do autor em tirar um dos personagens mais importantes da trama. Cria-se aí um mecanismo que manifesta claramente como se tecem estratégias de um diálogo social entre audiência e produção*.

Um belo exemplo para o conceito de mediação é proposto por Roger Silverstone, quando nos fala que:

[...] os significados mediados circulam em textos primários e secundários, através de intertextualidades infindáveis, na paródia e no pastiche, no constante replay e nos intermináveis discursos, na tela e fora da tela, em que nós, como produ- 
tores e consumidores, agimos e interagimos com pressa e urgência, procurando compreender o mundo, o mundo da mídia, o mundo mediado, o mundo da mediação ${ }^{22}$.

Não é o desejo propor aqui uma leitura puramente positiva do fenômeno. É claro que ele vem embutido em contexto sociohistórico e, como destaca Ien $\mathrm{Ang}^{23}$, enquanto análise das relações entre TV e suas audiências, precisamos levar em conta as estratégias de poder e controle exercidas pelo sistema de comunicação no qual a TV está inserida.

Mas há que destacar que a mobilização ocorrida em torno da morte de Juvenal Antena em Duas Caras resulta da ativação de competências culturais por parte da produção e da criação de mecanismos de resposta por parte do público, e que, até prova em contrário, são próprios da telenovela brasileira. Isto é, aquela que, no conjunto da teledramaturgia internacional, se caracteriza como obra em aberto: produto nacional que é escrito enquanto é realizado e veiculado e que permite um diálogo permanente entre produção e audiências em participação, ao mesmo tempo em que é também criado e produzido em meio a estratégias de controle e poder.

\section{A DIMENSÃO EDUCATIVA DA TELENOVELA: TÉCNICA, AGENDAS POLÍTICAS E CAMPANHAS SOCIAIS}

Mesmo que tenha uma forte presença em nossa realidade cultural; mesmo que seja um dos produtos da mídia mais assistidos pela população brasileira; mesmo que tenha ampla aceitação no mercado internacional, ainda é muito freqüente encontrarmos uma crítica que desvaloriza a telenovela. Não se pretende fazer aqui uma defesa incondicional deste gênero narrativo. $\mathrm{O}$ fato é que o gênero encontrou na produção brasileira um de seus maiores potentes espaços de criação. A indústria brasileira vem ao longo dos últimos cinqüenta anos realizando uma teleficção de altíssima qualidade técnica, com traços estéticos muito particulares, força de autoria com a participação de atrizes e atores da maior expressão dramática que temos no Brasil. Neste sentido, a telenovela se torna educativa pelo modo técnico como é realizada. Não se trata também de defender nenhum padrão Globo de qualidade; o fato é que temos ali uma escola que provê talentos para o cinema contemporâneo e até mesmo para as suas mais próximas concorrentes: a Record e o SBT.

Há uma outra questão a ser ressaltada: trata-se de pensarmos que, apesar de estar imersa no contexto do mercado cultural e tendo que atender às suas demandas, ainda assim é possível identificar uma série de agendas políticas tematizadas pelas entrelinhas da teleficção. Em um estudo recente ${ }^{24}$ tivemos como objetivo, entre outras questões, analisar as agendas políticas presentes em determinado produto (a telenovela A Indomada $a^{25}$, também de Aguinaldo Silva, veiculada em 1997). Foram identificadas as seguintes agendas: crítica direta ao comportamento corrupto, ao patriarcado, aos conflitos de classe e de
22. SILVERSTONE, Roger. Por que estudar a mídia? São Paulo: Loyola, 1999. p. 34.

23. ANG, len. Desperately seeking the audience (Procurando a audiência desesperadamente). London: Routledge, 1991.

24. LOPES, Maria Immacolata V.; BORELLI, Sílvia; RESENDE, Vera. Vivendo com a telenovela: mediações, recepção e teleficionalidade. São Paulo: Summus, 2002.

25. De Aguinaldo Silva e Ricardo Linhares. Direção de Marcos Paulo. Rede Globo de Televisão, fev./ out. 1997. 
orientação sexual e ao racismo, bem como a problematização do alcoolismo e a inclusão de pessoas com necessidades especiais. Um exercício de análise desta dimensão política da telenovela pode motivar debates renovados sobre a inserção da mídia nas sociedades contemporâneas e ajudar a revelar "como a reflexividade estética se processa" ${ }^{26}$.

Para finalizar, é preciso lembrar que também a inclusão de campanhas sociais utilizadas por uma ampla gama de autores é outro aspecto que define a telenovela brasileira. Cada vez mais os autores embutem nas tramas da ficção campanhas de interesse nacional e fazem da telenovela um coro grego para o drama da vida social, como foi destacado de modo brilhante por Roger Silverstone $^{27}$, e também com freqüentes reiterações para o debate político.

Por todo o exposto nestas breves páginas, precisamos cada vez mais discriminar nosso olhar ante a telenovela brasileira e avançar para além de um preconceito desinformado, de uma crítica maniqueísta e da falta de valorização do trabalho criativo que se faz no Brasil.

\section{REFERÊNCIAS BIBLIOGRÁFICAS}

ANG, Ien. Desperately seeking the audience. London: Routledge, 1991.

BORELLI, Sílvia Helena S.; PRIOLLI, G. A deusa ferida: por que a Rede Globo não é mais campeã absoluta de audiência. São Paulo: Summus, 2000.

BUCKINGHAM, David. Crescer na era das mídias. São Paulo: Loyola, 2007.

GIDDENS, A.; BECK, U.; LASH, S. Modernização reflexiva. São Paulo: Unesp, 1995.

LASH, Scott. A reflexividade e seus duplos: estrutura, estética e comunidade. In: LOPES, Maria Immacolata V.; BORELLI, Sílvia; RESENDE, Vera. Vivendo com a telenovela: mediações, recepção e teleficcionalidade. São Paulo: Summus, 2002.

MACHADO, Arlindo. A TV levada a sério. São Paulo: Senac, 2001.

MARTÍN-BARBERO, Jesús. Dos meios às mediações. Rio de Janeiro: Editora UFRJ, 1994.

OROFINO, Maria Isabel. Mídias e mediação escolar: pedagogia dos meios, participação e visibilidade. São Paulo: Cortez, 2005.

26. LASH, Scott. A reflexividade e seus duplos: estrutura, estética e comunidade. In: GIDDENS, A.; BECK, U.; LASH, S. Modernização reflexiva. São Paulo: Unesp, 1995.

27. SILVERSTONE, Roger. Por que estudar a mídia?, op. cit.
Mediações na produção de teleficção: um estudo sobre o Auto da Compadecida. Porto Alegre: EdiPUCRS, 2006.

PALLOTTINI, Renata. Dramaturgia de televisão. São Paulo: Moderna, 1998.

REDE GLOBO, Comunicação Corporativa (arquivo pessoal).

SILVERSTONE, Roger. Por que estudar a mídia? São Paulo: Loyola, 1999.

Television and everyday life. London: Routledge, 1994. 
WILLIAMS, Raymond. Cultura. São Paulo: Paz e Terra, 1992.

Culture and society (1780-1950). London: Penguin Books, 1977 (1958).

Marxismo e literatura. Rio de Janeiro: Zahar Editores, 1979.

Problems in materialism and culture. London: Verso, 1980.

Television, technology and cultural form. New York: Schocken Books, 1975.

The long revolution. London: Penguin Books, 1965 (1961).

WOLF, Mauro. Teorias da comunicação. Lisboa: Presença, 1987. 